\title{
M-Learning: An Educator for Future
}

\author{
Mohd. Rashid \\ Dept. of Computer Science \\ Career College, Bhopal
}

\author{
Swati Namdev \\ Dept. of Computer Science \\ Career College, Bhopal
}

\begin{abstract}
As mobile phones are getting smarter and more widely used, they have become a well-known tool in our surroundings. Mobile phones become popular in the society and many people can afford the cost, the demand of mobility is extended to teaching and learning purposes. Using mobile as a learning tool calls for services that are compatible with the concept of communication tools. Mobile learning formally M-Learning refers to the use of small, portable hand-held devices (smartphones) that usually operate in a wireless environment, and have a connection to the Internet. This paper entitled "MLearning: An Educator for Future" highlights the various issues involved in mobile learning, its need and how can mobile learning help us as educator in future.
\end{abstract}

\section{Keywords}

Educator, M-Learning, mobile, portable, teaching

\section{INTRODUCTION}

Mobile learning will encounter a world where "the environment has become the interface," where knowledge building and intelligence amplification have become like breathing.[1] As our society is entering a knowledge-based, Internet/Web-driven economy, education becomes a necessity for any individual who wants to be competitive and successful, regardless of his or her age, gender and contest. Mobile learning formally known as M-Learning has now become known as a new wave of development, based on the use of mobile devices combined with wireless infrastructure. The wireless technologies of the mobile revolution have seen the worldwide explosion of wireless communication devices. As part of a growth trend in the e-learning market, mobile learning is growing into a dynamic, interactive and personalized experience for learners.

Today's ICT has drastically extended the scope for learning anywhere, anytime and the term m-learning has gained serious strength and influence in describing the future of education. From a pedagogical perspective, mobile learning supports a new dimension in the educational process.[2] Mobile technologies has made it possible to provide learning opportunities to learners that are either without infrastructure for access or business professionals who are continually on the move or too busy during business hours. With pressure emerging in growing competition in a globalized market, rapid shifts in technology, most organizations have adopted the use of mobile phones and other mobile electronic devices as business tools. The advent of E-Learning was hailed as a marvelous opportunity for learners to access learning in ways that were previously not possible. [3] M-Learning is a natural extension to conventional e-learning practice and has the potential of making learning more widely accessible. Through M-Learning, mobile technology allows a greater degree of access to learning resources. Currently, most e-learning experiences are based on learners accessing resources through fixed nodes such as desktop PCs, to which access is generally restricted by either location, time of day or both. Central to Mlearning is the ideal of ubiquitous or ambient learning in which access to learning resources is truly independent of time and place.

Sorting out the promises and perils for m-learning is itself a challenge because research in this area is limited and the technology's capabilities are changing rapidly. Nevertheless, the potential for mobile devices to make substantial contributions to education is high. Evidence-based knowledge about how to use computers effectively, drawn from research in education, psychology, communications, neuroscience, engineering, and other disciplines, will help us avoid past missteps. [4]

\section{SIGNIFICANCE OF M-LEARNING}

Mobility:One of the primary significance of M-learning is that it reduces limitation of learning place; it focuses on the mobility of learner and learning. Mobile devices can be used anywhere, and any time, including at home, college, or even in traveling. Mobile phone's size, weight and wireless network connectivity propose it fully functional mobility which permits learning to take place anywhere and at anytime.

In trend:Generally young students are mostly adopters of new technologies because newness has its place in life. Today's mobiles are not just a communicative device of students for many it is a part of life. Young students use the mobile phone as a way of expressing their sense, style and lavish life, in this way mobile phones are now became a representative tool of trend.

Storage capacity:Mainly mobile phone memory comes in two different types. Inbuilt memory called internal memory and expendable memory called external memory. Both memories can be used to data storage; we can save our essential data or files on memory card. There are so many mobile phones available today which have more internal and support more external memory, which helps learner to store up, modify and share educational data or files for M-learning.

Capability of computer:significantly mobile devices have many of the efficient capabilities of modern computers, especially smart phones and PDA phone devices, which help learner to sustain various learning software of M-learning.

Frequent Connectivity:Connectivity is the most important feature of M-learning. With the help of a strong connectivity network, one can connect and interact with each other. There are various mobile applications like Bluetooth, Wi-Fi, infrared which assist user to connect with other devices and users. It offers an interactive learning experience where learners can interact with each other.

Easy to Use:Today mobiles are became a very handy device. It is easier to carry everywhere, we can access information, 
take photographs, record our thoughts with one device, and we can share these with our friends, colleagues which make mobile phone as user as friendly and personal device.

Cheap in Price:At the beginning mobile was considered a luxury. The price of a handset and call rates was beyond the reach of an ordinary person, but in present condition price fall, increasing demand and liberalization in government policy have given rise to mobile revolution. In general mobile devices are cheaper than desktop computers which concern as basic accessory for E-learning. It is easier to accommodate several mobile devices in a classroom than several desktop computers.

Best Multimedia Device:Mobile devices are not a single utility tool but it is a multi-utility device which engages learners through providing rich media content like music, videos, games and other entertaining and informational content which make it best multimedia device.

Sharing Capacity:Basically, all the multimedia mobile phones have the capacity of transferring information between mobile to mobile or mobile to PC. A USB cable is a fast and reliable data transfer method between a phone and a PC. A serial cable is a reliable connection method between a phone and a PC. Infrared connects mobile device wirelessly to PC or other mobile device within a short range. Bluetooth wireless technology connects mobile device wirelessly to $\mathrm{PC}$ or other mobile device within a short range. In this way these connections help learner to exchange data with other people and gain considerable knowledge. [5]

\section{KEY CHALLENGING ISSUES OF M- LEARNING}

Technical:The technical challenges of M-Learning areconnectivity, battery life, global IT support, continuing growth of broad band wireless networks, low resolution of displays, variety of operating system etc.Developing useful mlearning applications is challenging from a technical point of view, unlike computer operating systems, where Windows dominates and Mac and Linux have small market shares, cell phone operating systems diverge considerably. The field is very competitive, and major players include Google's Android, Apple's iPhone, Blackberry, Palm, Windows Mobile, and Symbian. This diversity means that developers who want to create an m-learning "app" must make multifaceted choices. To some extent, they play smartphone roulette when they choose just one platform, and some will probably become wiped out, but creating multiple versions is costly. Developers may choose to bypass this dilemma, and instead develop mobile friendly web sites.

Usability:The small screen size, miniscule QWERTY keyboards, and the 12 button numeric keypads, combine to make usability one of the key challenges for m-learning. Engineers are developing frameworks for evaluating usability on these devices, drawing on common tasks that users will likely want to accomplish. Navigating the menu, opening applications, and entering text are examples. Users want common tasks to be spontaneous and easily accomplished without having to read technical manuals. Students will have little patience with awkward user interfaces for m-learning applications.

Social and Educational: The social and educational challenges are- accessibility barriers, to develop an appropriate theory of learning for the mobile age, design of technology to support life time learning, tracking of results and proper use of this information, how to access learning outside the classroom, how to support learning across many countries, content security or pirating issues, frequent changes in devices models/technologies/functionality etc.

Other Issues: Apart from above mentioned challenges, there are other challenges like- conceptual differences regarding MLearning, no relation on learning time table, personal and private information and content, no demographic learning, access to and use of the technology in developing countries, and also wireless access in the classroom will encourage or enable unethical is another being challenge.[6]

\section{PRESENT TRENDS OF M-LEARNING IN INDIA}

M-learning in India at present is still in its infancy. However, the future promises to be an exponential market. There exists future possibility for this market to register double-digit growth. Acceptance in India will happen on account of the need of access for learning material due to the shortage of time, the ubiquity of power-point presentation tutorials, ebooks, videos, etc., as learning objects as these are being adopted in schools and educational institutions as a preferred media for teaching and learning. Some notable M-learning examples in India are:

Popular IT training institutes like Aptech Learning Services have already developed this platform in order to meet the present educational needs of corporate and institutions.

Major mobile manufacturers such as Nokia, Sony and Samsung have tied up with service providers like Airtel, Vodafone and others to provide mobile content, which also includes learning content. Companies that specialize in content aggregation provide the actual content. Mobile value added service (VAS) providers develop the mobile technology and delivery. Most of these companies have already launched their services pan in India and even GRE exams are available on the M-learning platform.

Various training and learning related content for organizations, educational institution, etc. pushed to users through mobile application over SMS, USSD, etc. by Spice, Tata DoCoMo etc.

M-learning is also seen as an additional tool to spread literacy in India beside conventional training programs, as presently mobile penetration in India is second only to radio and television. This is also possible because handset manufacturers in India are increasingly providing local language support to increase their geographical reach and penetrate existing market better. Most of the entry- and midmarket handsets available in India support user interfaces in Hindi, Marathi, Gujarati, Tamil, Bengali, Kannada, Malayalam, Telugu and Punjabi.

Libraries have been changing their role from the storehouses of information to providing access to information. Various digitization initiatives are being undertaken. The government of India with the collaboration of C-DAC (Centre for Development of Advanced Computing) aims at bringing one million books of digital library at the doorsteps of the common citizens. Several projects like the NSDL (National Science Digital Library) and VidyaVahini projects are under way. [7] 


\section{FUTURE OF M-LEARNING}

We already live in an era where our interaction with technology can be simplified and governed by technology providers. Almost in every field, they will assist us in identifying trends, making decisions, and providing data based on the context of your location, activity, time of day, etc. I seriously doubt they will take over our lives; however we will trust them more and more to make sense of large volumes of data. Facilitated by the increasing functionalities of mobile devices and global connectivity, learners in the future are likely to have more opportunities to construct their own knowledge and shape their own learning experiences. New technologies will provide unprecedented access to formal online courses, open-access journals and rich peer reviewed content. Students will take on a more active role in determining what and how they learn, while teachers will act as curators and guides, helping students navigate and benefit from the dizzying number of educational resources accessible via mobile technologies. The ability to collect and analyse vast amounts of learner-generated data will be a major factor in the development of mobile learning over the next fifteen years. Researchers engaged with online learning, intelligent tutoring systems, virtual labs, simulations and learning management systems are currently exploring ways to better understand and use learning analytics to improve teaching and learning in the future. [8]

\section{CONCLUSION}

The world of mobile and wireless computing is evolving fast and learning technology is moving towards mobile learning era. Computing technology has been applied to E-learning for more than three decades, but in recent years the rapid growth of mobile technologies is promising a new revolution in learning. M-learning is advanced form of E-learning which originated for supporting E-Learning. We can say it is a revolutionary E-learning which comes with lots of potential for teaching learning process. M-learning is a new way of learning which makes learning portable, spontaneous, efficient and exciting. The most important future of Mlearning is it decreases limitation of learning location. The ease of use, mobility and personalization aspects of mobile devices makes it an ideal medium for this next step in Elearning. M-learning is the future learning. In order to have proper functioning of the mobile Internet for learning, the elearning community must focus on the performance and productivity issues rather than traditional lecture style training or courseware. The Indian educational industry is in evolving stage. India might well be one of the leading countries to adopt M-learning in coming years owing to the number of young users. Naturally, they shift from 'd-Learning' to 'eLearning' and now from 'e-Learning' to ' $\mathrm{m}$ - Learning' will be the next huge wave, which will modernize the education in India and can play the role as an educator in future.

\section{REFERENCES}

[1] Rick Oller (May 2012): "The Future of Mobile Learning”, Educause, Center for Applied Research.

[2] Nitin Upadhyay, "M-Learning - A New Paradigm in Education," International Journal of Instructional Technology and Distance Learning, Vol.-3, No.-2.pp. 2734, Feb 2006

[3] Mercy Ayoma and Dr. Robert Oboko, "M-Learning Support Services For Corporate Learning," International Journal of Societal Applications of Computer Science, Issue 2, Vol 2 pp. 210-215, February 2013.

[4] Dr. Patricia Wallace: M-Learning: Promises, Perils, and Challenges for K-12 Education.http:// education.jhu.edu /PD/newhorizons/Journals/Winter2011/Wallace.

[5] AbhijitMitra, "Mobile Communication Devices as a Tool of Educational Process: a Brief Reference to Indian Scenario," Bhatter College Journal of Multidisciplinary Studies, Vol.-II, pp. 33-41, December 2012.

[6] Manoj Singh Rana, "Acknowledging Futuristic Methods of The Learning Scenario to be Adopted," InternationalJournal of Behavioral Social and Movement Sciences, Issue 04, Vol.01 pp. 185-194, October 2012.

[7] AbhijitMitra, "Mobile Communication Devices as a Tool of Educational Process: a Brief Reference to Indian Scenario," Bhatter College Journal of Multidisciplinary Studies, Vol.-II, pp. 33-41, December 2012.

[8] Carly Shuler, Niall Winters and Mark West (2013), "The Future of Mobile Learning Implications for Policy Makers and Planners," The United Nations Educational, Scientific and Cultural Organization (UNESCO). 